\title{
Identification of Growth Promoting Effect of $r$ BCG/BCG Culture Supernatant and Its Potential Applications
}

\author{
Tom H. Jin *, Tianli Qu, Anant Raina, Eric Tsao
}

Aeras, Rockville, USA.

Email: ${ }^{*}$ zjin@aeras.org

Received February $27^{\text {th }}, 2013$; revised March $30^{\text {th }}, 2013$; accepted April $10^{\text {th }}, 2013$

Copyright (C) 2013 Tom H. Jin et al. This is an open access article distributed under the Creative Commons Attribution License, which permits unrestricted use, distribution, and reproduction in any medium, provided the original work is properly cited.

\begin{abstract}
Background: Although BCG is the most widely administered vaccine in the world, there have never been as many cases of TB as there are now. Globally, more than 8.8 million people developed active TB and 1.4 million-many of them - died in 2010. It is estimated that half of pulmonary TB cases arise from latent Mtb infection, making the study of latency and reactivation of utmost importance. Methods: Widely administered BCG vaccines and a gene modified recombinant BCG ( $r$ BCG) strain, AERAS-422, were used as models to investigate the growth promoting function of resuscitation-promoting factors (Rpfs) in different bacilli culture phases. Different supernatant fractions were prepared by ultrafiltration, and the promoting function of each fraction containing secreted $\mathrm{Rpf}(\mathrm{s})$ was evaluated by growth curve monitoring and colony counting on 7H10 agar plates. Results: The promoting effect of culture supernatants was mainly associated with the high molecular weight fraction $(>30 \mathrm{kDa})$, which stimulated bacterial growth, but did not extend the exponential phase of stimulated culture. Anti-RpfB antibody showed significant growth restriction of the tested cultures. When comparing $r \mathrm{BCG}$ cultures containing $7 \mathrm{H} 9$ medium, the 10 - $30 \mathrm{kDa}$ fraction, or the $>30 \mathrm{kDa}$ fraction, only the $>30 \mathrm{kDa}$ fraction was displayed with down-regulation of the secretion of RpfC, D and E. In colony counting tests, the plates containing the $>30 \mathrm{kDa}$ fraction had total countable colony numbers 2 to 3 fold higher than the plates with the 10 - $30 \mathrm{kDa}$ fraction, and colonies appeared one to two weeks earlier than on the regular plates. The potential applications of the prepared supernatant fractions containing RpfA and RpfB are discussed, which may include accelerating diagnosis of $M t b$ infection and future TB vaccine development.
\end{abstract}

Keywords: Resuscitation-Promoting Factors (Rpfs); rBCG/BCG; Culture

\section{Introduction}

Tuberculosis (TB) is a serious and highly contagious disease affecting millions of people worldwide. Despite efforts to control and treat tuberculosis, in 2010, more than 8.8 million people developed active TB and 1.4 million-many of them-died [1]. Mycobacterium tuberculosis (M. tuberculosis or Mtb), the bacterium that causes tuberculosis, is estimated to be harbored by one-third of the world's population [2]. It is believed that the bacilli of $M t b$ are able to persist in vivo for long periods by entering into a latent state from which they may reactivate to cause the active pulmonary form of TB and also transmit the infection to others. It is estimated that globally half of pulmonary TB cases arise from latent $M t b$ infection, making the study of latency and reactivation of utmost importance $[3,4]$.

A major breakthrough has been the discovery of re-

"Corresponding author. suscitation-promoting factor (Rpf) from Micrococcus luteus, which is an extremely potent anti-dormancy factor [5-9]. It was shown recently that $M t b$ also expresses 5 Rpf proteins (RpfA, B, C, D, and E) that are homologous to Rpf, and have a strong similarity to a lysozyme-like enzyme previously implicated in reactivation of dormant bacteria both in vitro and in vivo [10-12]. The Rpf-like proteins of $M$. tuberculosis stimulate bacterial growth in laboratory culture at very low (pM) concentrations, which effectively excludes the possibility that they are simply being used as nutrients [11]. The rpf gene homologues of $M$. tuberculosis, Rv0867c (rpfA), Rv1009 (rpfB), Rv1884c (rpfC), Rv2389c (rpfD), and $R v 2450 c$ ( $r p f E$ ), have been demonstrated to stimulate the growth of stationary-phase mycobacteria, including Mycobacterium bovis $\mathrm{BCG}$ and $M$. tuberculosis [13-15]. However, the growth promoting function of each Rpf to latency bacilli, and the relationship of the five Rpfs to M. tuber- 
culosis growth, have not been clearly elucidated. The application of the promoting function of these proteins has not been extensively studied. We propose that the widely used TB vaccine, the attenuated strain named bacilli of Calmette and Guérin (BCG), and a gene modified recombinant $\mathrm{BCG}(r \mathrm{BCG})$ strain, might be good models to fulfill this purpose. In this study, different supernatant fractions containing secreted $\operatorname{Rpf}(\mathrm{s})$ were prepared from $\mathrm{BCG}$ or $r \mathrm{BCG}$ culture, and the promoting function of each fraction with respect to different stages of bacterial growth was evaluated. The potential applications of Rpfs identified by Western Blot, especially RpfA and RpfB, are discussed.

\section{Materials and Methods}

\subsection{BCG Strains and Growth Condition}

AERAS-422 rBCG (Ag85A, Ag85B, Rv3407, sureC: pfoAG137Q, $\Delta$ panCD) is a live attenuated $r \mathrm{BCG}$ strain being developed by Aeras [16,17]. Danish BCG 1331 was bought from Statens Serum Institut, Denmark. Chinese BCG strain was a gift from Shanghai Institute of Biological Products, China. Bacteria were inoculated in Middle brook $7 \mathrm{H} 9$ medium (BD, USA) plus the following components: $0.2 \% \mathrm{Na}$ glutamate (EMD), $0.05 \%$ Tyloxapol (Sigma), 2\% Glycerol, 0.03\% $\mathrm{ZnSO}_{4}, 2 \% \mathrm{MgSO}_{4}$ (J T Baker) and 2\% Dextrose (Fisher Scientific). Baffled bottom conical flasks were used with $125 \mathrm{rpm}$ at $37^{\circ} \mathrm{C}$. $7 \mathrm{H} 10$ agar plates were bought from BD, USA.

\subsection{Preparation of Culture Supernatant and Fractions}

\subsubsection{Centrifugation and Filter Sterilization}

Supernatant was prepared from the fifth day culture of $r$ BCG/BCG when Optical Density (OD) reached $4.5 \pm$ 0.5 . The culture was centrifuged at $2400 \times g$ for $20 \mathrm{~min}$. The supernatant was filter sterilized on a $0.22 \mu \mathrm{m}$ member after being slowly poured out in a Biological Safety cabinet.

\subsubsection{One Step Cut-Off Ultrafiltration}

A one step cut-off ultrafiltration was used to prepare different fractions of molecular weight (MW) greater than $10 \mathrm{kDa}, 30 \mathrm{kDa}$ and $100 \mathrm{kDa}(>10 \mathrm{kDa},>30 \mathrm{kDa}$, and $>100 \mathrm{kDa}$, respectively) of the filter-sterilized supernatant. The supernatant was transferred to a $200 \mathrm{~mL}$ cup ultrafiltration device (Amicon, Millipore) equipped with a $10 \mathrm{kDa}, 30 \mathrm{kDa}$ or $100 \mathrm{kDa}$ membrane. Nitrogen gas was connected to force the supernatant through the membrane. When retentate volume was reduced to around 10 $\mathrm{mL}$, the ultrafiltration cup was gently washed and refilled up to $200 \mathrm{~mL}$ with fresh $7 \mathrm{H} 9$ Middlebrook medium broth (VWR). The ultrafiltration process was repeated two more times. The final retentate volume was adjusted to achieve 25-fold concentration based on the starting volume. The ultrafiltration process was performed in a $2^{\circ} \mathrm{C}$ to $8^{\circ} \mathrm{C}$ room. The final prepared fractions were filtersterilized using a $0.22 \mu \mathrm{m}$ membrane.

\subsubsection{Two Step Cut-Off Ultrafiltration}

The supernatant fraction with MW between 10 and 30 $\mathrm{kDa}$ was prepared the same way as the one step cut-off ultrafiltration, except $30 \mathrm{kDa}$ and $10 \mathrm{kDa}$ membranes were used in sequence. After the filter-sterilized supernatant passed through the $30 \mathrm{kDa}$ membrane, the filtrate containing $<30 \mathrm{kDa}$ fraction of the supernatant was continually ultrafiltered on the $10 \mathrm{kDa}$ membrane. The final retentate of the 10 to $30 \mathrm{kDa}$ fraction $(10-30 \mathrm{kDa})$ was adjusted to achieve 25 -fold concentration based on the starting supernatant volume, and then filter-sterilized.

\subsection{Growth Promoting Test with Prepared Fractions of Culture Supernatant}

$10 \mathrm{~mL}$ of each filter-sterilized supernatant fractions (MW of $>10 \mathrm{kDa}, 10-30 \mathrm{kDa},>30 \mathrm{kDa}$, and $>100 \mathrm{kDa}$ ) were added to $190 \mathrm{~mL} 7 \mathrm{H} 9$ medium. $r \mathrm{BCG}$ or BCG was inoculated at a starting concentration of $10^{7} \mathrm{CFU} / \mathrm{mL}$. Two hundred $\mathrm{mL}$ of $7 \mathrm{H} 9$ broth only was used as a control. To eliminate the growth interference of left-over nutrition, the target fraction was concentrated and re-suspended with $7 \mathrm{H} 9$ medium in triplicate during the ultrafiltration process. OD at $600 \mathrm{~nm}$ of each culture was measured daily from $48 \mathrm{hr}$ post-inoculation.

To select the optimum promoting volume of the $>30$ $\mathrm{kDa}$ fraction for bacterial growth, $r \mathrm{BCG}$ was inoculated and cultured $7 \mathrm{H} 9$ medium containing 5,10 or $20 \mathrm{~mL}$ of the $>30 \mathrm{kDa}$ fraction.

\subsection{Growth Promoting Test on 7H10 Agar Plate}

Thawed $r \mathrm{BCG}$ frozen bulk was serially diluted to $10^{-6}$, $10^{-7}$ and $10^{-8}$ with $7 \mathrm{H} 9$ medium broth. $100 \mu \mathrm{L}$ diluted bacteria were mixed with $50 \mu \mathrm{L}$ of the $>30 \mathrm{kDa}$ or $10-$ $30 \mathrm{kDa}$ filter-sterilized fraction, or $50 \mu \mathrm{L} 7 \mathrm{H} 9$ broth as a control. Then $100 \mu \mathrm{L}$ of the mixture was directly dropped or spread by sterile glass beads on $7 \mathrm{H} 10$ plates. The resulting colonies were counted on day 14 or 21 , and representative photographs were taken by Protocol Colony Counter (Microbiology Inc.) (12). There were a total of 27 plates used in three dilutions for each sample lot; the average CFU counting from each lot was calculated, and representative plates are shown.

\subsection{Antibody Inhibition Assay}

The antibody inhibition assay was executed with antiRpfA and/or anti-RpfB rabbit serum. The process is the same as "Growth promoting test on 7H10 agar plate," described above, except that $2 \mu \mathrm{L}$ or $5 \mu \mathrm{L}$ of anti-RpfB 
rabbit serum, $5 \mu \mathrm{L}$ of anti-RpfA rabbit serum, or $5 \mu \mathrm{L}$ of both anti-RpfA and anti-RpfB rabbit sera were first mixed with $998 \mu \mathrm{L}(1: 500)$ or $995 \mu \mathrm{L}(1: 200)$ diluted bacteria $(\mathrm{E}+6$ or $\mathrm{E}+7)$, then $300 \mu \mathrm{L}$ of the mixture was transferred and mixed with $150 \mu \mathrm{L}$ of the $>30 \mathrm{kDa}$ or 10 - $30 \mathrm{kDa}$ supernatant fraction, or $150 \mu \mathrm{L} 7 \mathrm{H} 9$ broth as a control, with a final volume of plating at $100 \mu \mathrm{L}$, plated in triplicate. The plates were incubated at $37^{\circ} \mathrm{C}$ for 21 days; the resulting colonies were counted by Protocol Colony Counter. The average CFU counting from each group was calculated.

\subsection{Inter-Regulation Function among Rpfs}

The bacteria were grown as described above in "Growth promoting test with prepared fractions of culture supernatant". From the fourth to the eleventh day, samples were taken from each culture (7H9 medium, 7H9 medium with the $>30 \mathrm{kDa}$ fraction or $10-30 \mathrm{kDa}$ fraction) to detect the inter-regulation function of different Rpfs by Western Blotting.

\section{Results}

\subsection{Growth Promoting (GP) Effect of Ultrafiltration Treated Fractions from Culture Supernatant}

\subsubsection{Fraction with $\mathrm{MW}$ of $>10 \mathrm{kDa}$ or $>100 \mathrm{kDa}$}

The GP effect of culture supernatant was first tested using the $>10 \mathrm{kDa}$ or $>100 \mathrm{kDa}$ fraction. $r \mathrm{BCG}$ was inoculated in parallel in culture medium of $7 \mathrm{H} 9$ or $7 \mathrm{H} 9$ plus the $>10 \mathrm{kDa}$ or $>100 \mathrm{kDa}$ supernatant (Figure 1). The culture inoculated with the $>10 \mathrm{kDa}$ supernatant fraction grew faster than the regular 7H9 medium and medium containing the $>100 \mathrm{kDa}$ fraction after inoculation. At the $125^{\text {th }}$ hour, the $\mathrm{OD}_{600 \mathrm{~nm}}$ of $r \mathrm{BCG}$ was 6.44 for the culture

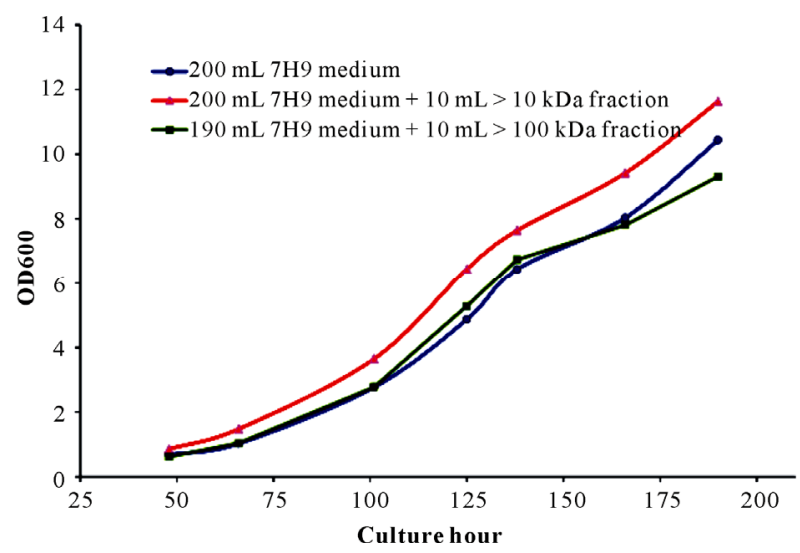

Figure 1. Growth promoting effect of $>10 \mathrm{kDa}$ or $>100 \mathrm{kDa}$ fraction of culture supernatant. Recombinant BCG was inoculated and cultured in $200 \mathrm{~mL} 7 \mathrm{H} 9$ medium or $190 \mathrm{~mL}$ $7 \mathrm{H} 9$ medium plus $10 \mathrm{~mL}$ of $>10 \mathrm{kDa}$ or $>100 \mathrm{kDa}$ fraction generated from culture supernatant. with the $>10 \mathrm{kDa}$ fraction compared to 4.86 for the $7 \mathrm{H} 9$ medium only and 5.28 for the culture containing the $>100 \mathrm{kDa}$ supernatant. The same trend was maintained until the endpoint of testing. The growth curves of $r \mathrm{BCG}$ cultured in medium and medium containing the $>100$ $\mathrm{kDa}$ fraction were similar.

\subsubsection{Fraction with $\mathrm{MW}$ of $>30 \mathrm{kDa}$ or 10 to $30 \mathrm{kDa}$}

The GP effect of culture supernatant was narrowed down to fractions with MW of 10 to $30 \mathrm{kDa}$ and $>30 \mathrm{kDa}$ (Figure 2) ( $r$ BCG, Danish BCG 1331 and Chinese BCG displayed the same growth pattern, data not shown). From around $95 \mathrm{hr}$, the culture inoculated with the $>30$ $\mathrm{kDa}$ fraction started to grow faster than medium alone or medium with the 10 to $30 \mathrm{kDa}$ fraction. At $140 \mathrm{hr}$, its $\mathrm{OD}_{600 \mathrm{~nm}}$ reached 8.6, which was significantly higher than the other two cultures ( 6.45 for the medium only and 6.72 for the culture with 10 to $30 \mathrm{kDa}$ fraction). This faster growth pattern was maintained during the entire exponential phase. The culture inoculated with the 10 $30 \mathrm{kDa}$ fraction showed a delayed fast growth tendency from around 200 to $245 \mathrm{hr}$, however, this fast growth only lasted a short period of time. During 245 to $260 \mathrm{hr}$, all three cultures quickly fell into their death phase. However, the bacterial growth with the $>30 \mathrm{kDa}$ fraction dropped significantly faster compared to the other two cultures.

\subsubsection{Optimum Promoting Volume of $>30 \mathrm{kDa}$ Fraction}

The optimum promoting volume of the $>30 \mathrm{kDa}$ fraction for growth of $r \mathrm{BCG}$ in $200 \mathrm{~mL}$ culture was tested in 7H9 medium containing 5,10 or $20 \mathrm{~mL}$ of the prepared $>30$ $\mathrm{kDa}$ fraction (Figure 3). All cultures inoculated with the $>30 \mathrm{kDa}$ fraction components grew consistently faster

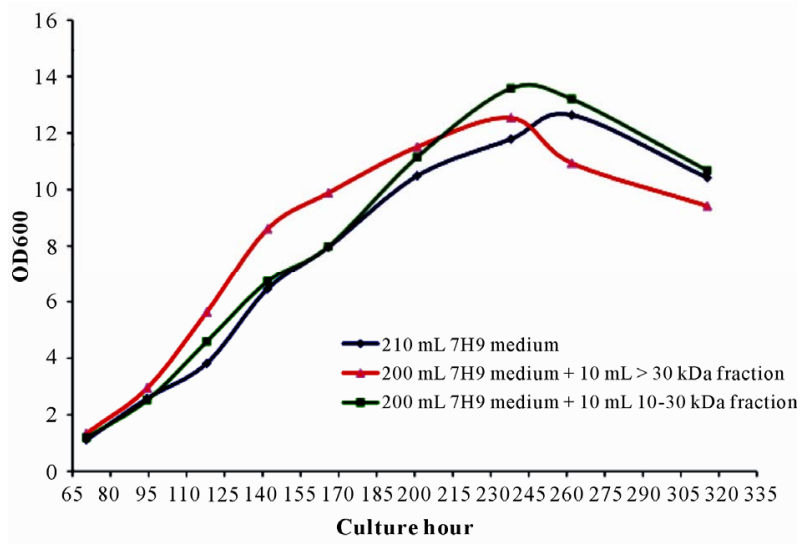

Figure 2. Growth promoting effect of $>30$ and $10-30 \mathrm{kDa}$ fractions of culture supernatant. Recombinant BCG were inoculated and cultured in $200 \mathrm{~mL} 7 \mathrm{H9}$ medium or $190 \mathrm{~mL}$ $7 \mathrm{H} 9$ medium plus $10 \mathrm{~mL}$ of $>30 \mathrm{kDa}$ or 10 - $30 \mathrm{kDa}$ fractions generated from culture supernatant. 


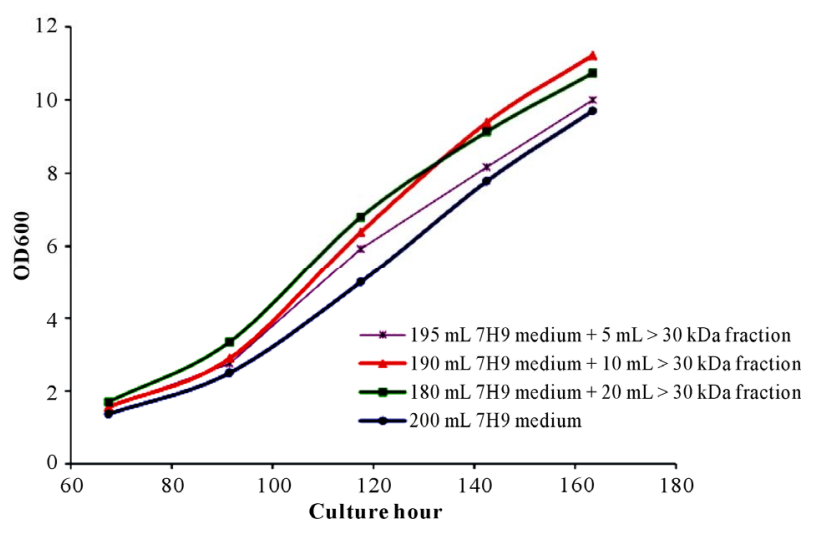

Figure 3. Dose/volume and growth response pattern induced by $>30 \mathrm{kDa}$ fraction of culture supernatant. Recombinant BCG was inoculated and cultured in $7 \mathrm{H9}$ medium or $7 \mathrm{H9}$ medium containing 5,10 or $20 \mathrm{~mL}$ of $>30 \mathrm{kDa}$ fraction generated from culture supernatant.

than the control medium inoculated culture. A dose/ volume response pattern was observed, with increased volume of the $>30 \mathrm{kDa}$ fraction resulting in increased GP effect through around $130 \mathrm{hr}$. At $144 \mathrm{hr}$, growth of the culture inoculated with $20 \mathrm{~mL}$ of the $>30 \mathrm{kDa}$ fraction slowed and was overtaken by the culture inoculated with $10 \mathrm{~mL}$ of the $>30 \mathrm{kDa}$ fraction. The increased growth of the culture inoculated with $10 \mathrm{~mL}$ vs $20 \mathrm{~mL}$ of the $>30$ $\mathrm{kDa}$ fraction was maintained through the final time point at $164 \mathrm{hr}$. The optimum protoming volume of $10 \mathrm{~mL}$ of the $>30 \mathrm{kDa}$ fraction mixed with $190 \mathrm{~mL} 7 \mathrm{H} 9$ medium was selected for the rest of the Rpf studies.

\subsection{Growth Promoting Test on $7 \mathrm{H10}$ Agar Plate}

When a diluted bacterial mixture containing the $>30 \mathrm{kDa}$ fraction was dropped or spread on $7 \mathrm{H} 10$ agar plates, the colonies were observed clearly on the $14^{\text {th }}$ day, with colonies appearing one to two weeks earlier than the ones on the regular $7 \mathrm{H} 10$ plates (data not shown). After the bacteria mixed with the $>30 \mathrm{kDa}$, or $10-30 \mathrm{kDa}$ fraction, or control medium, were spread and incubated at $37^{\circ} \mathrm{C}$ for 3 weeks, the countable colony number $(\mathrm{CN})$ from the plate having the $>30 \mathrm{kDa}$ fraction was 326 (at serial dilution of E +6; Figure 4(a)), which was 2 to 3 fold higher than the plate containing the $10-30 \mathrm{kDa}$ fraction $(\mathrm{CN}$ of 112) or the regular 7H10 plate (CN of 121), or (Figures 4(b) and (c)).

\subsection{Growth Inhibition by Anti-RpfB}

The growth inhibition effect of anti-RpfA and anti-RpfB was investigated in $r$ BCG plating samples containing the $>30 \mathrm{kDa}$ supernatant fraction. As expected, anti-RpfB showed significant inhibition of cell growth stimulated by the $>30 \mathrm{kDa}$ fraction. After the plates were incubated at $37^{\circ} \mathrm{C}$ for 21 days, the colony count was 137 (at serial

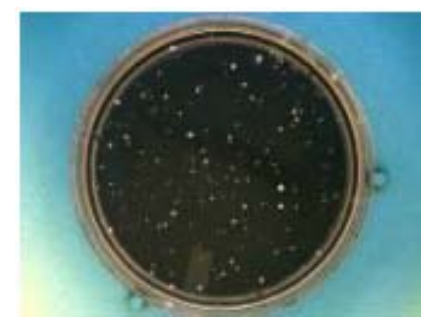

(a)

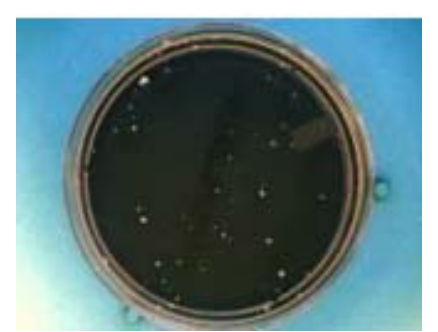

(b)

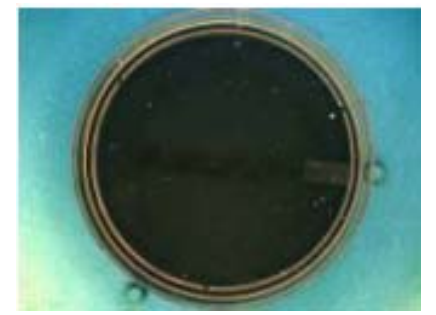

(c)

Figure 4. Growth promoting effect of different supernatant fractions detected on $7 \mathrm{H10}$ plate. (a) (CN: 326): $100 \mu \mathrm{L}$ diluted $r B C G$ mixed with $50 \mu \mathrm{L}$ of $>30 \mathrm{kDa}$ fraction and spread on 7H10 plate; (b) (CN: 112): $100 \mu \mathrm{L}$ diluted $r$ BCG mixed with $50 \mu \mathrm{L}$ of 10 - $30 \mathrm{kDa}$ fraction and spread on 7H10 plate; (c) (CN: 121): $100 \mu \mathrm{L}$ diluted $r$ BCG directly spread on regular $7 \mathrm{H} 10$ plate. Note: the plates were counted at the 21 day (dilution at $\mathrm{E}+6$ ); $\mathrm{CN}$ : countable colony number.

dilution of $E+7)$ for the plate without anti-RpfB, and 74 or 19 for the plate having $2 \mu \mathrm{L}$ or $5 \mu \mathrm{L}$, respectively, of pre-mixed anti-RpfB. Adding anti-RpfB did not totally inhibit bacterial growth on the solid agar plates. In a further test, adding $5 \mu \mathrm{L}$ anti-RpfA instead of anti-RpfB did not show a growth inhibition effect, with an average CFU of 71, which was similar to the control without antiRpfA and anti-RpfB $(\mathrm{CFU}=70)$. However, adding $5 \mu \mathrm{L}$ of both anti-RpfA and anti-RpfB resulted in reduction of the CFU count to 12 .

\subsection{Down-Regulation Function of $>30 \mathrm{kDa}$ Fraction}

As shown in Figure 5, during the culture period from day 4 to 11, the secretion of RpfC, RpfD and RpfE was down-regulated (samples in lane 2) when bacteria were grown in $7 \mathrm{H} 9$ medium containing the $>30 \mathrm{kDa}$ supernatant fraction. This down-regulation phenomenon was 


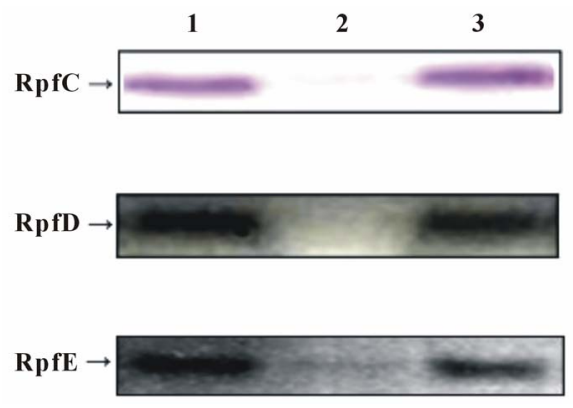

Figure 5. Growth inter-regulation function of different supernatant fractions. Lane 1: RpfC, $D$ and $E$ were examined in the culture grown in 7H9 medium; Lane 2: RpfC, D and E were examined in the culture grown in $7 \mathrm{H9}$ medium containing > $30 \mathrm{kDa}$ supernatant fraction; Lane 3: RpfC, D and $E$ were examined in the culture grown in $7 \mathrm{H} 9$ medium containing 10 - $30 \mathrm{kDa}$ fraction. Note: the inspection of each culture was executed from day 4 to 11 , and the band patterns were similar.

not detected by Western Blotting in samples from the cultures of regular 7H9 medium (lane 1) and 7H9 medium containing the $10-30 \mathrm{kDa}$ fraction (lane 3 ).

\section{Discussion}

Rpf is a secreted and muralytic enzyme that increases the culturability of dormant bacteria $[5,18,19]$. Recently, considerable progress has been made in understanding the structure, function and physiological role of Rpfs in different organisms, most notably the major human pathogen, Mycobacterium tuberculosis, which encodes multiple rpf-like genes [11,12]. A key unresolved question, however, concerns the relationship between the predicted biochemical activity of Rpfs - cleavage of the $\beta-1,4$ glycosidic bond in the glycan backbone of peptidoglycan - and the their effect on culturability. In $M$. tuberculosis, the interacting protein A (RipA) enables Rpfs to synergistically degrade peptidoglycan to facilitate growth. Furthermore, the combined action of Rpfs with RipA and other peptidoglycan hydrolases might produce muropeptides that could exert diverse biological effects through host and/or bacterial signaling, the latter involving serine/threonine protein kinases [20-25]. This suggests that the activation of latent $M t b$ requires peptidoglycan hydrolysis, which either alters the mechanical properties of the cell wall to facilitate cell division or releases lysis products that function as anti-dormancy signals.

Our data showed that only the high MW, but not the low MW fraction resulted in an apparent GP effect in bacterial growth and division. The data suggest that RpfA and/or RpfB were/was playing a key role in enhancing cell growth. Several studies have resulted in similar conclusions. Wu et al. demonstrated that RpfB could promote proliferation of M. tuberculosis in liquid and on solid media [26]. Tufariello et al. reported that of the five Rpf deletion mutants being tested, the RpfB deletion exhibited a delayed reactivation phenotype, manifested by delayed post-reactivation growth kinetics and prolonged median survival times among infected animals $[14,15]$. Russell-Goldman et al. showed that a double RpfA and RpfB deletion mutant exhibited reactivation deficiency in vivo. They found the reactivation deficiency of $\triangle \mathrm{rpfAB}$ was more severe and persisted longer than that of a single RpfB or RpfA deletion in chronically $M t b$-infected mice [27]. In M. tuberculosis, the role of $r p f B$ appears to be non-redundant in pathogenesis [15]. However, it still needs to be clarified whether RpfB or RpfB plus RpfA in combination with RipA could fulfill complete GP function for bacilli to grow or reactivate. Anti-RpfB showed significant inhibition of cell growth stimulated by the $>30 \mathrm{kDa}$ fraction. Although adding anti-RpfB could not totally inhibit bacterial growth on solid agar plates, our data showed that the major GP function to stimulate BCG bacilli to multiply and divide was generated from RpfB.

The next important question is what is the relationship among Rpf proteins? The gene expression profiling of strains with a single $r p f$ deletion was reported by Downing et al. [28]. They showed that there was a significant overlap or functional redundancy in the differential gene expression profile of $r p f B$ to $r p f E$ (but not $r p f A$ ) mutants. In addition, five cognate proteins could stimulate bacterial growth at picomolar concentrations [11]. Our study showed a different activation pattern among these Rpf proteins. Comparing the $r \mathrm{BCG}$ cultures with $7 \mathrm{H} 9$ medium, and $7 \mathrm{H} 9$ medium plus the $10-30$ or $>30 \mathrm{kDa}$ supernatant fraction, only the culture with the $>30 \mathrm{kDa}$ fraction containing RpfA and RpfB could completely inhibit the secretions of RpfC to RpfE from day 4 to 11 (during exponential phase). This suggests that RpfB and/ or RpfA were/was involved in down-regulating the expression of $r p f C$ to $r p f E$ in order to permit their promoting effect to fully function. Gene expression of $r p f$ may be regulated in a growth phase-dependent manner. This important regulation needs further tests to clarify.

The Rpfs identified in BCG/rBCG culture supernatants, especially RpfB and RpfA, have varied potential applications: 1) as tools to study the important role in controlling the growth, latency and reactivation of $M t b ; 2$ ) adding growth-promoting factor(s) in medium could reduce culture incubation time, increase the accuracy of the CFU potency test, and reduce the construction period of a $r$ BCG candidate strain; 3) incorporating Rpfs into fermentation medium could improve the manufacturing productivity of live $\mathrm{BCG} / r \mathrm{BCG}$ vaccine, if the culture is being harvested at growth phase with a relatively high proportion of viable cells; 4) the Rpf family might be employed in early diagnosis of $M t b$ infection or as vac- 
cine components to provide interesting opportunities to treat and prevent mycobacterial infections.

In conclusion, the high MW and low MW fractions of $\mathrm{BCG} / r \mathrm{BCG}$ culture supernatant were prepared by a stepultrafiltration process. Only the high MW fraction containing RpfA and RpfB showed an apparent promoting effect of bacterial growth. Adding the high MW fraction into cell culture resulted in inhibition of expression and down-regulation of low MW Rpfs. Further study of Rpfs could expand the understanding of latency and reactivation of M. tuberculosis, thereby permitting accelerated diagnosis of $M t b$ infection and future TB vaccine development.

\section{Acknowledgements}

The authors are grateful to Barbara Shepherd for her critical review of the manuscript. This work was supported by the Bill \& Melinda Gates Foundation.

\section{REFERENCES}

[1] World Health Organization, "Global Tuberculosis Control Report 2011,”2011.

[2] B. R. Bloom and C. J. Murray, "Tuberculosis: Commentary on a Reemergent Killer," Science, Vol. 257, No. 5073, 1992, pp. 1055-1064. doi:10.1126/science.257.5073.1055

[3] S. M. Arend and J. T. van Dissel, "Evidence of Endogenous Reactivation of Tuberculosis after a Long Period of Latency," The Journal of Infectious Diseases, Vol. 186, No. 6, 2002, pp. 876-877. doi:10.1086/342604

[4] J. Chan and J. Flynn, "The Immunological Aspects of Latency in Tuberculosis," Clinical Immunology, Vol. 110, No. 1, 2004, pp. 2-12. doi:10.1016/S1521-6616(03)00210-9

[5] G. V. Mukamolova, A. S. Kaprelyants, D. I. Young, M. Young, D. B. Kell, "A Bacterial Cytokine," Proceeding National Academy Science, Vol. 95, No. 15, 1998, pp. 8916-8921. doi:10.1073/pnas.95.15.8916

[6] G. V. Mukamolova, S. S. Kormer, D. B. Kell and A. S. Kaprelyants, "Stimulation of the Multiplication of Micrococcus Luteus by an Autocrine Growth Factor," Archives of Microbiology, Vol. 172, No. 1, 1999, pp. 9-14. doi:10.1007/s002030050733

[7] G. V. Mukamolova, A. G. Murzin, E. G. Salina, G. R. Demina, D. B. Kell, A. S. Kaprelyants and M. Young, "Muralytic Activity of Micrococcus Luteus Rpf and Its Relationship to Physiological Activity in Promoting Bacterial Growth and Resuscitation," Molecular Microbiology, Vol. 59, No. 1, 2006, pp. 84-98. doi:10.1111/j.1365-2958.2005.04930.x

[8] G. V. Mukamolova, O. A. Turapov, K. Kazarian, M. Telkov, A. S. Kaprelyants, D. B. Kell and M. Young, "The Rpf Gene of Micrococcus Luteus Encodes an Essential Secreted Growth Factor," Molecular Microbiology, Vol. 46, No. 3, 2002, pp. 611-621. doi:10.1046/j.1365-2958.2002.03183.x

[9] G. V. Mukamolova, N. D. Yanopolskaya, D. B. Kell and A. S. Kaprelyants, "On Resuscitation from the Dormant State of Micrococcus Luteus," Antonie Van Leeuwenhoek, Vol. 73, No. 3, 1998, pp. 237-243. doi:10.1023/A:1000881918216

[10] S. Biketov, G. V. Mukamolova, V. Potapov, E. Gilenkov, G. Vostroknutova, D. B. Kell, M. Young and A. S. Kaprelyants, "Culturability of Mycobacterium tuberculosis Cells Isolated from Murine Macrophages: A Bacterial Growth Factor Promotes Recovery," FEMS Immunology Medical Microbiology, Vol. 29, No. 4, 2000, pp. 233-240. doi:10.1111/j.1574-695X.2000.tb01528.x

[11] G. V. Mukamolova, O. A. Turapov, D. I. Young, A. S. Kaprelyants, D. B. Kell and M. Young, "A Family of Autocrine Growth Factors in Mycobacterium Tuberculosis," Molecular Microbiology, Vol. 46, No. 3, 2002, pp. 623-635. doi:10.1046/j.1365-2958.2002.03184.x

[12] V. V. Yeremeev, T. K. Kondratieva, E. I. Rubakova, S. N. Petrovskaya, K. A. Kazarian, M. V. Telkov, S. F. Biketov, A. S. Kaprelyants and A. S. Apt, "Proteins of the Rpf Family: Immune Cell Reactivity and Vaccination Efficacy against Tuberculosis in Mice," Infection and Immunity, Vol. 71, No. 8, 2003, pp. 4789-4794. doi:10.1128/IAI.71.8.4789-4794.2003

[13] R. K. Gupta, B. S. Srivastava and R. Srivastava, "Comparative Expression Analysis of Rpf-Like Genes of Mycobacterium tuberculosis H37Rv Under Different Physiological Stress and Growth Conditions," Microbiology, Vol. 156, No. Pt9, 2010, pp. 2714-2722. doi:10.1099/mic.0.037622-0

[14] J. M. Tufariello, W. R. Jacobs Jr. and J. Chan, "Individual Mycobacterium tuberculosis Resuscitation-Promoting Factor Homologues are Dispensable for Growth in Vitro and in Vivo," Infection and Immunity, Vol. 72, No. 1, 2004, pp. 515-526. doi:10.1128/IAI.72.1.515-526.2004

[15] J. M. Tufariello, K. Mi, J. Xu, Y. C. Manabe, A. K. Kesavan, J. Drumm, K. Tanaka, W. R. Jacobs Jr. and J. Chan, "Deletion of the Mycobacterium tuberculosis Resuscitation-Promoting Factor Rv1009 Gene Results in Delayed Reactivation from Chronic Tuberculosis," Infection and Immunity, Vol. 74, No. 5, 2006, pp. 2985-2995.

[16] H. J. Jin, L. Nguyen, T. Qu and E. Tsao, "Improved Formulation and Lyophilization Cycle for $r$ BCG Vaccine," Vaccine, 2011, Vol. 29, No. 29-30, pp. 4848-4852. doi:10.1016/j.vaccine.2011.04.056

[17] R. Sun, Y. A. Skeiky, A. Izzo, V. Dheenadhayalan, Z. Imam, E. Penn, et al., "Novel Recombinant BCG Expressing Perfringolysin O and the Over-expression of Key Immunodominant Antigen; Pre-Clinical Characterization, Safety and Protection against Challenge with Mycobacterium tuberculosis," Vaccine, Vol. 27, No. 33, 2009, pp. 4412-4423. doi:10.1016/j.vaccine.2009.05.048

[18] M. O. Shleeva, K. Bagramyan, M. V. Telkov, G. V. Mukamolova, M. Young, D. B. Kell and A. S. Kaprelyants, "Formation and Resuscitation of 'Non-Culturable' Cells of Rhodococcus Rhodochrous and Mycobacterium tuberculosis in Prolonged Stationary Phase," Microbiology, Vol. 148, No. Pt5, 2002, pp. 1581-1591. 


$$
\text { doi:10.1016/j.tube.2010.12.006 }
$$

[19] M. O. Shleeva, G. V. Mukamolova, M. Young, H. D. Williams and A. S. Kaprelyants, "Formation of 'NonCulturable' Cells of Mycobacterium Smegmatis in Stationary Phase in Response to Growth under Suboptimal Conditions and Their Rpf-mediated Resuscitation," Microbiology, Vol. 150, No. Pt6, pp. 1687-1697. doi:10.1099/mic.0.26893-0

[20] M. Cohen-Gonsaud, P. Barthe, C. Bagnéris, B. Henderson, J. Ward, C. Roumestand and N. H. Keep, "The Structure of a Resuscitation-promoting Factor Domain from Mycobacterium tuberculosis Shows Homology to Lysozymes," Nature Structural \& Molecular Biology, Vol. 12, No. 3, 2005, pp. 270-273. doi:10.1038/nsmb905

[21] E. C. Hett, M. C. Chao, L. L. Deng and E. J. Rubin, "A Mycobacterial Enzyme Essential for Cell Division Synergizes with Resuscitation-Promoting Factor," PLoS Pathogens, Vol. 4, No. 2, 2008, pp. 1-8. doi:10.1371/journal.ppat.1000001

[22] E. C. Hett, M. C. Chao, A. J. Steyn, S. M. Fortune, L. L. Deng and E. J. Rubin, "A Partner for the ResuscitationPromoting Factors of Mycobacterium tuberculosis," Molecular Microbiology, Vol. 66, No. 3, 2007, pp. 658-668. doi:10.1111/j.1365-2958.2007.05945.x

[23] A. Ruggiero, D. Marasco, F. Squeglia, S. Soldini, E. Pedone and C. Pedone, "Structure and Functional Regulation of RipA, a Mycobacterial Enzyme Essential for Daughter Cell Separation," Structure, Vol. 18, No. 9, 2010, pp. 1184-1190. doi:10.1016/j.str.2010.06.007

[24] A. Ruggiero, F. Squeglia, C. Esposito, D. Marasco, E.
Pedone, C. Pedone and R. Berisio, "Expression, Purification, Crystallization and Preliminary X-Ray Crystallographic Analysis of the Resuscitation Promoting Factor Interacting Protein RipA from M. tuberculosis," Protein \& Peptide Letters, Vol. 17, No. 1, 2010, pp. 70-73. doi:10.2174/092986610789909557

[25] A. Ruggiero, B. Tizzano, E. Pedone, C. Pedone, M. Wilmanns and R. Berisio, "Crystal Structure of the Resuscitation-Promoting Factor (DeltaDUF) RpfB from $M$. tuberculosis," Journal of Molecular Biology, Vol. 385, No. 1, 2009, pp. 153-162. doi:10.1016/j.jmb.2008.10.042

[26] X. Wu, Y. Yang, Y. Han, J. Zhang, Y. Liang, H. Li, B. Li and L. Wang, "Effect of Recombinant Rv1009 Protein on Promoting the Growth of Mycobacterium tuberculosis," Journal of Applied Microbiology, Vol. 205, No. 4, 2008, pp. 1121-1127. doi:10.1111/j.1365-2672.2008.03850.x

[27] E. Russell-Goldman, J. Xu, X. Wang, J. Chan and J. M. Tufariello, "A Mycobacterium tuberculosis Rpf DoubleKnockout Strain Exhibits Profound Defects in Reactivation from Chronic Tuberculosis and Innate Immunity Phenotypes," Infection and Immunity, Vol. 76, No. 9, 2008, pp. 4269-4281. doi:10.1128/IAI.01735-07

[28] K. J. Downing, J. C. Betts, D. I. Young, R. A. McAdam, F. Kelly, M. Young and V. Mizrahi, "Global Expression Profiling of Strains Harbouring Null Mutations Reveals That the Five Rpf-Like Genes of Mycobacterium tuberculosis Show Functional Redundancy," Tuberculosis, Vol. 84, No. 3-4, 2004, pp. 167-179. doi:10.1016/j.tube.2003.12.004 